\title{
Estimating the Time-Dependent Performance of Nanocatalysts in Fuel Cells Based on a Cost-Normalization Approach
}

\author{
Cinthia R. Zanata, ${ }^{a, b}$ Pablo S. Fernández, ${ }^{c}$ Alexandre B. Santos, ${ }^{d}$ Gabriel C. da Silva, ${ }^{e}$ \\ Giuseppe A. Camara ${ }^{b}$ and Cauê A. Martins* $* a$ \\ ${ }^{a}$ Faculdade de Ciências Exatas e Tecnologia, Universidade Federal da Grande Dourados, UFGD, \\ 79804-970 Dourados-MS, Brazil

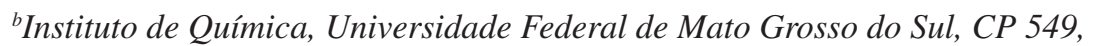 \\ 79070-900 Campo Grande-MS, Brazil \\ 'Instituto de Química, Universidade Estadual de Campinas, Cidade Universitária Zeferino Vaz, \\ Barão Geraldo, 13083-970 Campinas-SP, Brazil \\ ${ }^{d}$ Departamento de Engenharia de Produção, Universidade Federal de São Carlos, UFSCar, \\ 13565-905 São Carlos-SP, Brazil \\ eInstituto de Química de São Carlos, Universidade de São Paulo, IQSC-USP, \\ CP 780, São Carlos-SP, Brazil
}

\begin{abstract}
Researchers have developed new catalysts for fuel cells (FC), whose performances are compared after applying different normalization procedures. However, there is not a standard procedure. The current produced from $\mathrm{CO}$ electrooxidation was compared for $\mathrm{Pt}_{4} \mathrm{Ru}_{5} \mathrm{Sn}_{1} / \mathrm{C}$ and homemade $\mathrm{Pt} / \mathrm{C}$ nanoparticles (NPs) normalized by different methods and the use of different methods renders different interpretations. Since the whole field aims to maximize the cost-effectiveness, a complementary method to normalize currents and power in terms of the total cost of the nanocatalyst, the Catalyst-based Cost method $(\mathrm{CbC})$, was proposed. $\mathrm{CbC}$ considers the cost of all metals employed to build the catalyst, not only those ones with available surfaces. By applying a simple smoothing method on the prices in a time series, we were able to forecast the prices and consequently the power density of a FC. CbC provides tools for industrials forecast the designing of nanomaterials with improved efficiency and low cost.
\end{abstract} activity

Keywords: fuel cell, catalyst, normalization of current and power, cost of metal, forecasting

\section{Introduction}

The continuous growth of the energy demand opened a wide field of research for energy converters, among which fuel cells have been exhaustively studied. Fuel cells can produce energy with low environmental impact since they generate power by the oxidation of a fuel at the anode and reduction of $\mathrm{O}_{2}$ at the cathode. Fuel cells can be fed by $\mathrm{H}_{2}$ or small alcohols, as methanol and ethanol. The catalysts, both anodes and cathodes, are mainly based on $\mathrm{Pt}$, which is historically an expensive material. ${ }^{1}$ This is the main reason why many efforts have been made to replace Pt (at least partially) in catalysts used in fuel cells.

*e-mail: cauealvesmartins@gmail.com, cauemartins@ufgd.edu.br
When a new nanoparticle catalyst is produced, the normalization of the electrochemical current generated by its use is imperative in electrocatalysis, since this procedure allows distinct surfaces to be directly compared for a given reaction in terms of their intrinsic electroactivities. In this context, different normalization methods generate multiple interpretations about the activity of a catalyst. This lack of consensus hinders the comparison of different materials in terms of their electrochemical performances and generates impasses that prevent a faster development of the research area.

A method commonly used consists in normalizing the currents by the electrochemically active surface area (ECSA), which is highly useful but not easily accessed for many materials. For Pt-based catalysts (as PtRu/C 
and PtRuSn/C) the ECSA is sometimes estimated by the charge involved in the $\mathrm{H}$ desorption region..$^{2-5}$ For Pd-based catalysts, the ECSA is usually calculated by the charge involved in the reduction of a $\mathrm{PdO}$ monolayer. ${ }^{6-8}$ The main concern about using the ECSA for multi-metallic catalysts calculated by these methods lies on the fact that the metal lattice parameter suffers intense modifications when an additional element is inserted into its structure. ${ }^{9,10}$ In this context, the estimation of ECSA by stripping of CO rises as an alternative method for multi-metallic catalysts. ${ }^{11-13}$ However, such approach also present difficulties related to the determination of the charge involved in the electrooxidation. For instance, depending on the metal nature, $\mathrm{CO}$ can adsorb on different ways onto a surface, ${ }^{14,15}$ which can embed errors in estimating the surface area if pure metals are compared with multi-metallic catalysts. Another regular method is normalizing the current by the mass of the main metal (normally Pt) in multi-metallic catalysts. ${ }^{16-18}$ This approach attempts to focus on the reduction of the cost, assuming that such material shows better performance even when using lower contents of Pt. However, this procedure is misleading when expensive metals (as $\mathrm{Rh}$ or $\mathrm{Au}$ ) are used to replace Pt, because it disregards the cost of these materials.

As a general rule among of a plenty of options, researchers choose a particular method to highlight the characteristic they intend to emphasize. Very often, a candidate to catalyst is ruled out after initial studies based on these biased criteria. Because of this uncritical stance, many times additional studies performed after the seminal one reach controversial conclusions, since the same initial material is now highlighted due to its high performance, even using similar experimental setup. Such discrepancies probably result in misjudgment caused by the way researchers show and analyze the data.

In this sense, we used the $\mathrm{CO}$ electrooxidation reaction (COEOR) to compare the electrochemical performances of multi-metallic catalysts by using different methods of current normalization. Our results reveal a series of inconsistences concerning the interpretation of electrocatalytic activity of the materials investigated, depending on the method adopted for the normalization of currents. Furthermore, the aim of the whole field is the development of low cost materials with high electrochemical activity and stability, as shows the recurrent appeal for using less expensive materials. ${ }^{4,13,19-24}$ In this context, we propose an alternative method to normalize electrochemical currents and power densities based on the cost of the catalysts. This method is versatile since the results can be easily modified considering the price of the catalyst in the past, present and even in the near future.

\section{Experimental}

\section{Synthesis of carbon supported metallic nanoparticles}

Metallic nanoparticles (NPs) were synthesized by the chemical reduction method induced by ethylene glycol using polyvinylpyrrolidone (PVP) as capping agent. ${ }^{25}$ This simple method of synthesis combines reproducibility and quickness, yielding highly dispersed NPs over different kinds of carbons with narrow size distribution. ${ }^{25-27}$ We synthetized $\mathrm{PtRuSn} / \mathrm{C}$ and $\mathrm{Pt} / \mathrm{C}$. The chemical composition of each catalyst was, respectively, (i) $\mathrm{PtRuSn} / \mathrm{C}$ of atomic ratio 4:5:1 with $20 \%$ of metals load; and (ii) $\mathrm{Pt} / \mathrm{C}$ with $40 \%$ of metal load $(\mathrm{m} / \mathrm{m})$. We used the following protocol of synthesis for all catalysts: aqueous dispersions containing adequate amounts of the metallic precursors (i.e., $\mathrm{H}_{2} \mathrm{PtCl}_{6}, \mathrm{RuCl}_{3} \cdot \mathrm{xH}_{2} \mathrm{O}$ and $\mathrm{SnCl}_{2} \cdot \mathrm{H}_{2} \mathrm{O}$ ), carbon and PVP were mixed to a solution containing ethylene glycol/water $3: 1(\mathrm{v} / \mathrm{v})$ and heated at $150{ }^{\circ} \mathrm{C}$ for $2 \mathrm{~h}$. The $\mathrm{PVP} / \mathrm{metal}(\mathrm{s})$ molar ratio was set to 0.3 . The dispersions obtained (containing the NPs) were washed with water and centrifuged at $4500 \mathrm{rpm}$ for $1 \mathrm{~h}$. This process was repeated five times. The remaining dispersions were dried at $60{ }^{\circ} \mathrm{C}$ for $24 \mathrm{~h}$. The chemical composition of PtRuSn/C catalyst was determined by using a scanning electron microscope (SEM) JEOL (model JSM6380-LV) equipped with an energy-dispersive X-ray spectroscopy (EDS) detector. All experiments were made in triplicate.

\section{Half-cell electrochemical experiments}

Dispersions containing the nanoparticles (inks) were used as working electrodes by mixing $1 \mathrm{mg}$ of the respective powder of metallic nanoparticles dispersed on carbon with $2 \mathrm{~mL}$ of 2-propanol and $50 \mu \mathrm{L}$ of Nafion ${ }^{\circledR} \%(\mathrm{v} / \mathrm{v})$, followed by sonication for $30 \mathrm{~min}$. An aliquot of $50 \mu \mathrm{L}$ of each dispersion was deposited on a gold disk $\left(0.79 \mathrm{~cm}^{2}\right.$ of geometric area) kept at $50 \pm 2{ }^{\circ} \mathrm{C}$, followed by the addition of $50 \mu \mathrm{L}$ of a diluted Nafion ${ }^{\circledR}$ solution ( $1 \mathrm{~mL}$ of Nafion ${ }^{\circledR}$ 5\%:20 mL of 2-propanol).

All electrochemical experiments were carried out in a conventional three-electrode cell. The electrolytes were prepared with deionized water $(18.2 \mathrm{M} \Omega \mathrm{cm})$ and $\mathrm{HClO}_{4}$ (Merck). We used a Pt plate as counter electrode. The reference electrode was a reversible hydrogen electrode (RHE). Electrochemical data is presented in the RHE scale. All electrochemical runs were performed at $25{ }^{\circ} \mathrm{C}$ under oxygen-free conditions.

\section{Fuel cell experiments}

The electrodes used in the fuel cell experiments were 
prepared by a combined filtration/painting procedure, ${ }^{28}$ using carbon supported Pt catalysts $(20 \%$ metal/C by E-TEK), with the same metal loading of $\mathrm{Pt}_{4} \mathrm{Ru}_{5} \mathrm{Sn}_{1} / \mathrm{C}$ catalysts. To prepare the catalyst layer $\left(\mathrm{Pt} / \mathrm{C}\right.$ or $\left.\mathrm{Pt}_{4} \mathrm{Ru}_{5} \mathrm{Sn}_{1} / \mathrm{C}\right)$, a homogeneous dispersion of Nafion and NPs in 2-propanol was quantitatively deposited on the faces of the composite diffusion layer by painting procedure. Next, samples were cured at $80{ }^{\circ} \mathrm{C}$ for $1 \mathrm{~h}$. The metal loading was $0.4 \mathrm{mg}$ of metal $\mathrm{cm}^{-2}$, and the Nafion loading was $1.1 \mathrm{mg} \mathrm{cm}^{-2}$ for all electrodes. Membrane-electrode assemblies (MEAs) were made following a previous work. ${ }^{29}$ Namely, anode and cathode were hot pressed onto the Nafion 115 membrane at $125^{\circ} \mathrm{C}$ under a pressure of $50 \mathrm{MPa}$ for $2 \mathrm{~min}$. Experiments were carried out in single cells of $5 \mathrm{~cm}^{2}$ of active geometric area at operation temperature of $70{ }^{\circ} \mathrm{C}$. MEAs were kept wet using humidification bottles at 85 and $75{ }^{\circ} \mathrm{C}$, respectively. We used flows of 100 and $150 \mathrm{~mL} \mathrm{~min}^{-1}$ for pure $\mathrm{H}_{2}$ and $\mathrm{H}_{2} / 100 \mathrm{ppm} \mathrm{CO}$, respectively. The performances of the electrodes were evaluated from polarization curves. The curves in presence of $100 \mathrm{ppm} \mathrm{CO}$ were obtained keeping the cell at $0.7 \mathrm{~V}$ in pure $\mathrm{H}_{2}$ for $2 \mathrm{~h}$, followed by $2 \mathrm{~h}$ at $0.8 \mathrm{~V}$ in $\mathrm{H}_{2} / 100 \mathrm{ppm} \mathrm{CO}$ to reach a steady state. Two identical MEAs for each catalyst were tested to evaluate the repeatability of the experiments. Besides, the performance of the electrodes was evaluated from two consecutive cell polarization measurements, showing no changes among them.

\section{Results and Discussion}

The influence of the method of current normalization for multi-metallic nanoparticles

Whenever a new, multi-metallic catalyst is synthesized, it is almost consensual that its performance must be compared to a commercial or homemade $\mathrm{Pt} / \mathrm{C}$ catalyst which serves as a standard. ${ }^{17,18,23,24}$ Considering that CO-tolerant catalysts allow the use of low-cost $\mathrm{H}_{2}$ obtained from hydrocarbons reforming $\left(\mathrm{H}_{2}\right.$ containing traces of $\mathrm{CO}$ ), we choose $\mathrm{CO}$ electrooxidation reaction (COEOR) to investigate the influence of the method to normalize electrochemical current on the interpretation of the results. In this regard, we compare the CO-tolerance on PtRuSn/C and Pt/C NPs by performing COEOR in acid media. EDS data reveal an atomic composition of 4:5:1 for Pt:Ru:Sn (see Table S1 in the Supplementary Information section), thus we labeled it as $\mathrm{Pt}_{4} \mathrm{Ru}_{5} \mathrm{Sn}_{1} / \mathrm{C}$. The metal loads for $\mathrm{Pt} / \mathrm{C}$ and $\mathrm{Pt}_{4} \mathrm{Ru}_{5} \mathrm{Sn}_{1} / \mathrm{C}$ are 40 and $20 \%(\mathrm{~m} / \mathrm{m})$, respectively.

As a way to evaluate the activity of $\mathrm{Pt}_{4} \mathrm{Ru}_{5} \mathrm{Sn}_{1} / \mathrm{C}$ towards COEOR, we used three methods to normalize the currents: (i) the ECSA based on the charge $\left(210 \mu \mathrm{C} \mathrm{cm}^{-2}\right)$ involved in the desorption of hydrogen from Pt surface $;^{30}$ (ii) the mass of Pt, also named as specific activity or mass activity ${ }^{25-27}$ and (iii) a combination of area and Pt-mass. Results are depicted in Figures 1a, 1b and 1c, respectively. In this context, two important features to measure and compare the electrocatalysis of different materials are the onset potential and the current density. Figures 1a-c show that regardless the normalization procedure the COEOR onset potential on $\mathrm{Pt}_{4} \mathrm{Ru}_{5} \mathrm{Sn}_{1} / \mathrm{C}$ is ca. $0.3 \mathrm{~V}$ lower than on $\mathrm{Pt} / \mathrm{C}$, which merely confirms the well-known CO-tolerance of the multi-metallic catalyst. This result is unequivocal and is in line with previous reports..$^{24,28-31}$

Now, comparing the current densities, the scenario is more complex and different methods provide conflicting results. By using the ECSA, the current density produced on $\mathrm{Pt} / \mathrm{C}$ is higher than that on $\mathrm{Pt}_{4} \mathrm{Ru}_{5} \mathrm{Sn}_{1} / \mathrm{C}$ (Figure 1a). In other words, this result shows that $\mathrm{Pt} / \mathrm{C}$ is able to produce more current than $\mathrm{Pt}_{4} \mathrm{Ru}_{5} \mathrm{Sn}_{1} / \mathrm{C}$ per site occupied by $\mathrm{CO}$ molecules. The interpretation is opposite when using the Pt-mass to normalize currents. As shows Figure 1b, the specific activity (in terms of mg- $\mathrm{Pt}^{-1}$ ) is higher for COEOR on $\mathrm{Pt}_{4} \mathrm{Ru}_{5} \mathrm{Sn}_{1} / \mathrm{C}$ than on $\mathrm{Pt} / \mathrm{C}$. In other words, this result shows that $\mathrm{Pt}_{4} \mathrm{Ru}_{5} \mathrm{Sn}_{1} / \mathrm{C}$ is able to produce more current than $\mathrm{Pt} / \mathrm{C}$ per atom of $\mathrm{Pt}$ in each catalyst (even considering those atoms in the NPs bulk that do not interact directly with the electrochemical environment). This result is frequently found in literature and such inconsistences lead to confusing (and even misleading) interpretations regarding the catalytic activity of a specific material. In our case, the mass of $\mathrm{Pt}$ is obviously lower on $\mathrm{Pt}_{4} \mathrm{Ru}_{5} \mathrm{Sn}_{1} / \mathrm{C}$. Therefore, the high activity of $\mathrm{Pt}_{4} \mathrm{Ru}_{5} \mathrm{Sn}_{1} / \mathrm{C}$ could be a mathematical artifact that will always generate a "gain in catalytic activity" as long as the metal mixed with Pt does not lead to a decrease of current that counterbalance the effect caused by the lower Pt loads used in the multimetallic materials. Figure 1c shows a combination of ECSA and mass of Pt to normalize currents which leads to a huge COEOR current density on $\mathrm{Pt}_{4} \mathrm{Ru}_{5} \mathrm{Sn}_{1} / \mathrm{C}$. This method induces an erroneous idea that $\mathrm{Pt}_{4} \mathrm{Ru}_{5} \mathrm{Sn}_{1} / \mathrm{C}$ is massively more active than $\mathrm{Pt} / \mathrm{C}$.

The following discussion illustrates how the normalization method influences the final output and how the reader can be struck for a misinterpreted response. Here we used COEOR as an example, but similar misinterpretations can be made when evaluating the electroactivity of nanomaterials for other important reactions. In an attempt to move one step forward concerning the normalization methods of electrochemical data (and other power generation systems, as seen later) a new method based on the cost of the material was suggested. 


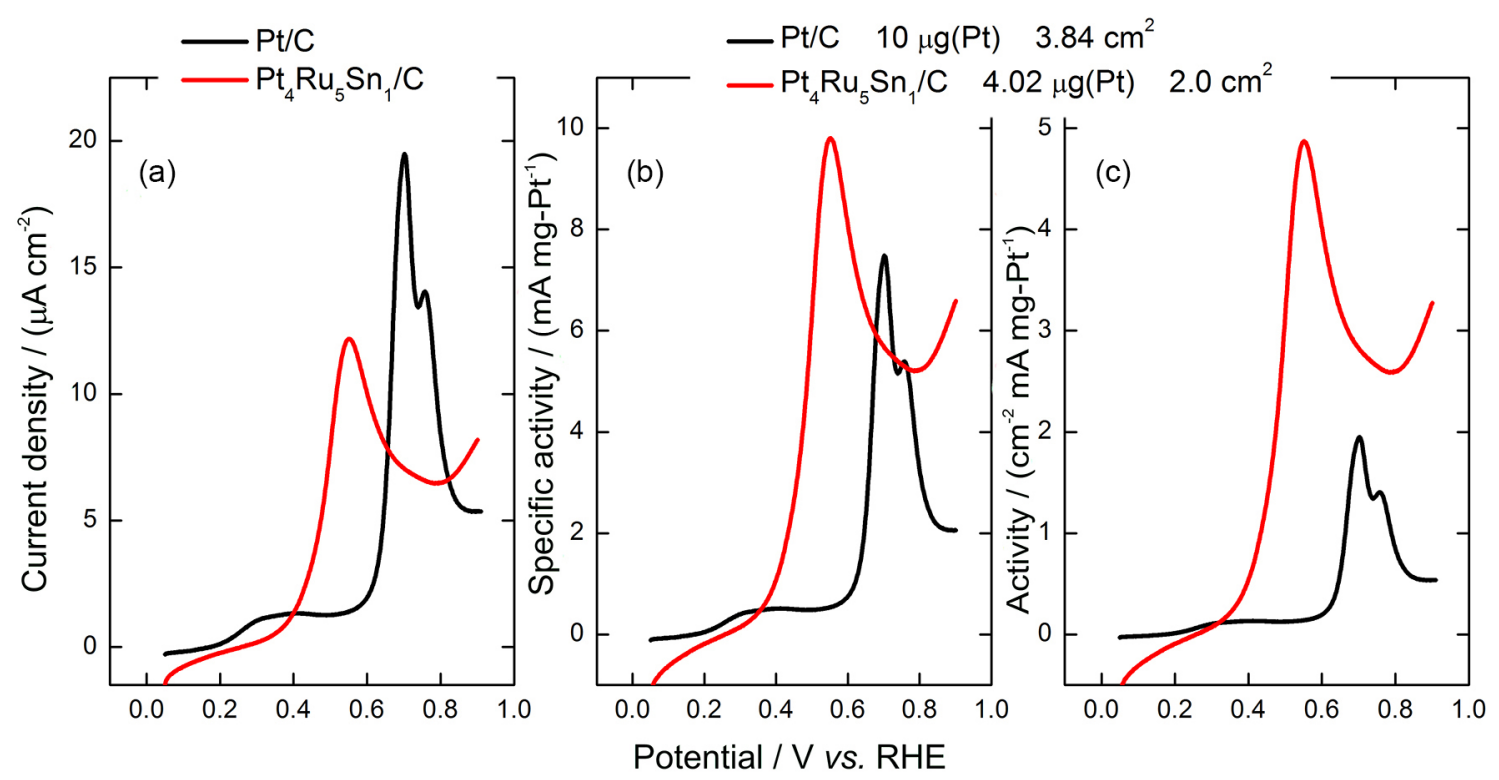

Figure 1. Stripping of $\mathrm{CO}$ on $\mathrm{Pt} / \mathrm{C}$ and $\mathrm{Pt}_{4} \mathrm{Ru}_{5} \mathrm{Sn}_{1} / \mathrm{C}$ performed in $0.1 \mathrm{~mol} \mathrm{~L}^{-1} \mathrm{HClO}_{4}$ at $0.005 \mathrm{~V} \mathrm{~s}^{-1}$. Current normalized by (a) the electrochemically active surface area; (b) mass of Pt; (c) a combination of surface area and mass of Pt.

\section{The Catalyst-based Cost for current normalization $(\mathrm{CbC})$}

The development of a new material with technological interest must consider the efficiency of the device and the cost of its components. In this process, the continuous monitoring of production costs (in order to keep them as low as possible) is a task that can generate a competitive advantage among the technology holders. Considering that the price and activity of a metal are the main reasons for its utilization, we suggest a new method to normalize electrochemical currents based on the total cost of the material, hereafter named Catalyst-based Cost method ( $\mathrm{CbC})$. In the $\mathrm{CbC}$ method the current is shown as a quotient between the current density and the total cost of those metals that constitute the catalyst. Figure 2 compares the electroactivity of $\mathrm{Pt}_{4} \mathrm{Ru}_{5} \mathrm{Sn}_{1} / \mathrm{C}$ and $\mathrm{Pt} / \mathrm{C}$ in terms of $\mathrm{CbC}$, here named activity by $\mathrm{CbC}$. To estimate the cost of metals, we used an average of the monthly price per gram of metal during one year (2014) taken from the stock exchange, as shown in Figure $\mathrm{S} 1$.

By using $\mathrm{CbC}$, we can clearly deduce that the use of $\mathrm{Pt}_{4} \mathrm{Ru}_{5} \mathrm{Sn}_{1} / \mathrm{C}$ is more advantageous than $\mathrm{Pt} / \mathrm{C}$ along of that period on time (2014). $\mathrm{Pt}_{4} \mathrm{Ru}_{5} \mathrm{Sn}_{1} / \mathrm{C}$ shows higher activity than $\mathrm{Pt} / \mathrm{C}$ due to its lower total cost, this fact added to the low onset potential make this material a promising CO-tolerant catalyst. In other words, it is possible to generate more electrochemical current by using $\mathrm{Pt}_{4} \mathrm{Ru}_{5} \mathrm{Sn}_{1} / \mathrm{C}$ than using $\mathrm{Pt} / \mathrm{C}$ for the same price, although we are not considering the intrinsically particularities about the stability of each catalyst at this point. Here, we should note that EDS is a semi-quantitative technique, thus the composition of the multi-metallic material is not exact. Anyway, even considering a composition uncertainty of $10 \%$ does not compromise the interpretation assumed here.

The cost of the material is directly proportional to its mass; hence $\mathrm{CbC}$ is similar to the Pt-mass normalization (Figure 1b), but not the same. There is a slight difference in terms of current density at ca. $0.7 \mathrm{~V}$, where the multimetallic catalyst displays better performance whether the mass of material is considered (comparing Figure 1b with Figure 2). The obvious disadvantage of the Pt-mass method lies on the fact that its application could easily generate a mathematical artifact (whether applied inadvertently, as shown previously) while $\mathrm{CbC}$ considers the cost of the whole material, not only the Pt-cost. Additionally, $\mathrm{CbC}$ considers the cost of all metals, including those completely and partially covered (by a capping agent or residues of synthesis, for instance). The cost of the catalyst should not be taken from an estimated mass calculated from the surface area; otherwise, one would exclude the cost of inactive particles. The $\mathrm{CbC}$ is a reliable method, which reflects the financial advantage of using the metallic composition of interest at that period on time and certainly is a powerful tool when allied to other methods.

Equations 1-3 summarize the most used methods for current normalization, where $\mathrm{j}$ is the normalized current, $\mathrm{i}$ is the non-normalized current and $\mathrm{m}_{\mathrm{Pt}}$ the mass of platinum. At this point is important to note that there are other methods currently used. ${ }^{32}$

$j=\frac{i}{E C S A}$ 


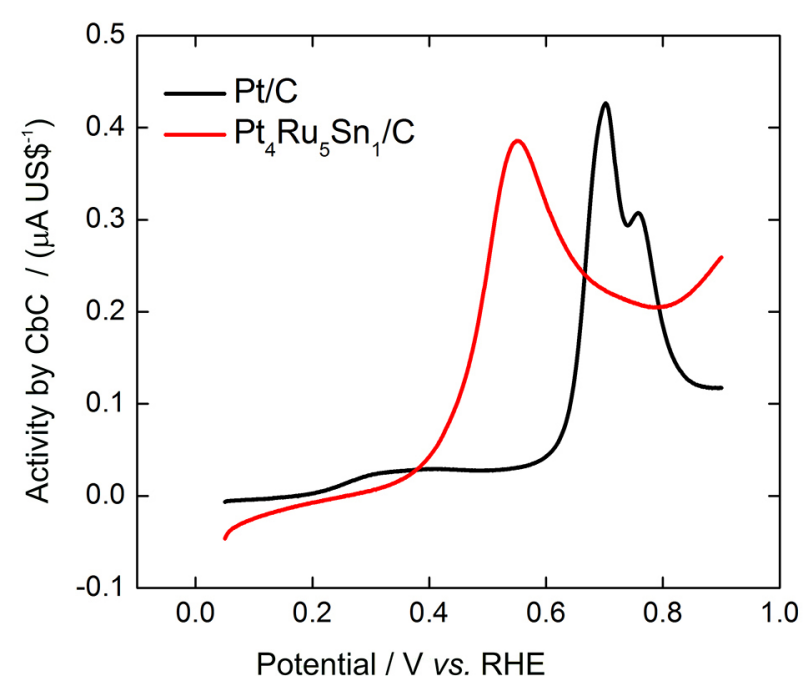

Figure 2. Stripping of $\mathrm{CO}$ on $\mathrm{Pt} / \mathrm{C}$ and $\mathrm{Pt}_{4} \mathrm{Ru}_{5} \mathrm{Sn}_{1} / \mathrm{C}$ performed in $0.1 \mathrm{~mol} \mathrm{~L}^{-1} \mathrm{HClO}_{4}$ at $0.005 \mathrm{~V} \mathrm{~s}^{-1}$. Current normalized by the Catalystbased Cost method.

$\mathrm{j}=\frac{\mathrm{i}}{\mathrm{m}_{\mathrm{Pt}}}$

$\mathrm{j}=\frac{\mathrm{i}}{\mathrm{ECSA} \times \mathrm{m}_{\mathrm{Pt}}}$

The difficulty in choosing the best method and the right stage of the experimental procedure to determine the ECSA makes hard to compare $j$ of a new catalyst with the literature. Additionally, the myriad of permutations including the mass of $\mathrm{Pt}$ to calculate $\mathrm{j}$ complicates the use of methods containing $\mathrm{m}_{\mathrm{Pt}}$ in the equation. The $\mathrm{CbC}$ method allows any researcher to introduce the annual price average of a material and to analyze how the activity (in terms of A per US\$) changes for the desired period, as shows equation $4 . \sum \$_{\mathrm{M}}$ is the sum of prices of all metals that constitute the catalyst (considering the mass experimentally used) and $\$_{M}$ is a function of time, $\$_{M}(t)$. Furthermore, the current density (or current) can be normalized quarterly, monthly or even daily.

Activity by $\mathrm{CbC}=\frac{\mathrm{i}}{\sum \$_{\mathrm{M}}}$

Although the mass of a metal remains constant, its cost varies with time. $\mathrm{CbC}$ is time dependent, which is not a disadvantage because the low prices of specifics catalysts claimed in several studies are obviously time dependent. The question that emerges is: "How to analyze the price fluctuation over time?" To answer this query, we need to follow a stock exchange. The fluctuation of current normalized by $\mathrm{CbC}$ during the time represents the efficiency of a catalyst considering its cost along the years. Using this new approach, any researcher is able to find the activity by $\mathrm{CbC}$ whether the mass of the used metal and the price in a period of time are provided. As an illustration of the feasibility of the method, we used $\mathrm{CbC}$ to estimate the activities of $\mathrm{Pt} / \mathrm{C}$ and $\mathrm{Pt}_{4} \mathrm{Ru}_{5} \mathrm{Sn}_{1} / \mathrm{C}$ in 1993, 2003 and 2011 (Figure S2). For those years, the multi-metallic catalyst is more active than $\mathrm{Pt} / \mathrm{C}$. Moreover, the growing in the annual average price of metals along the years results in a decrease of activity of both catalysts. However, the performance decrease is faster for $\mathrm{Pt} / \mathrm{C}$ than for $\mathrm{Pt}_{4} \mathrm{Ru}_{5} \mathrm{Sn}_{1} / \mathrm{C}$ due to the relative low prices of $\mathrm{Ru}$ and $\mathrm{Sn}$ in the multi-metallic catalyst (Figure S2). Also, researchers might include ECSA at the denominator of equation 4 whether the physicalchemical magnitude $\left(\mathrm{A} \mathrm{cm}^{-2}\right)$ is required.

The cost of power: a new way to look at fuel cells measurements

In order to apply $\mathrm{CbC}$ in a more realistic scenario, we investigated the power density of a $\mathrm{H}_{2} / \mathrm{O}_{2}$ fuel cell using $\mathrm{Pt}_{4} \mathrm{Ru}_{5} \mathrm{Sn}_{1} / \mathrm{C}$ and $\mathrm{Pt} / \mathrm{C}$ (E-TEK) as anodes. For both configurations $\mathrm{Pt} / \mathrm{C}$ (E-TEK) was used as cathode. Concerning the power density and the CO-tolerance, the multi-metallic catalyst showed results in agreement with the literature. ${ }^{33}$ All polarization curves show the classical regions; activation, ohmic drop and masstransport polarization (Figure 3a). Both electrodes present significant activation and ohmic decay, mostly due to the well-known kinetic limitation of the oxygen reduction reaction. Figure $3 b$ shows that the activation and ohmic decay are even higher for $\mathrm{Pt} / \mathrm{C}$ in the presence of $\mathrm{CO}$, while $\mathrm{Pt}_{4} \mathrm{Ru}_{5} \mathrm{Sn}_{1} / \mathrm{C}$ presents higher current densities at potentials higher than $0.4 \mathrm{~V}$, which evidences the improved CO-tolerance of the multi-metallic catalyst. ${ }^{33,34}$ The commercial catalyst presents better performance than the synthesized one for pure $\mathrm{H}_{2}$ electrooxidation, characterized by the higher current density and consequently, higher power density in the whole potential range.

Applying $\mathrm{CbC}$ to normalize the power of the single cells using $\mathrm{Pt} / \mathrm{C}$ and multi-metallic catalysts, we are directly considering the price of the catalyst needed to generate power. Here, we point out that there are more variables (as the proton exchange membrane) which contribute to the price of fuel cells. However, (i) the major contribution to the price comes from noble metals and (ii) all the other constituent parts are common to all configurations. Figure 4 shows the power density of the same single cell normalized by $\mathrm{CbC}$. Here the power curves of Figure 3a were normalized by the annual average cost of metals (W US $\$^{-1}$ ). We show the power density in 


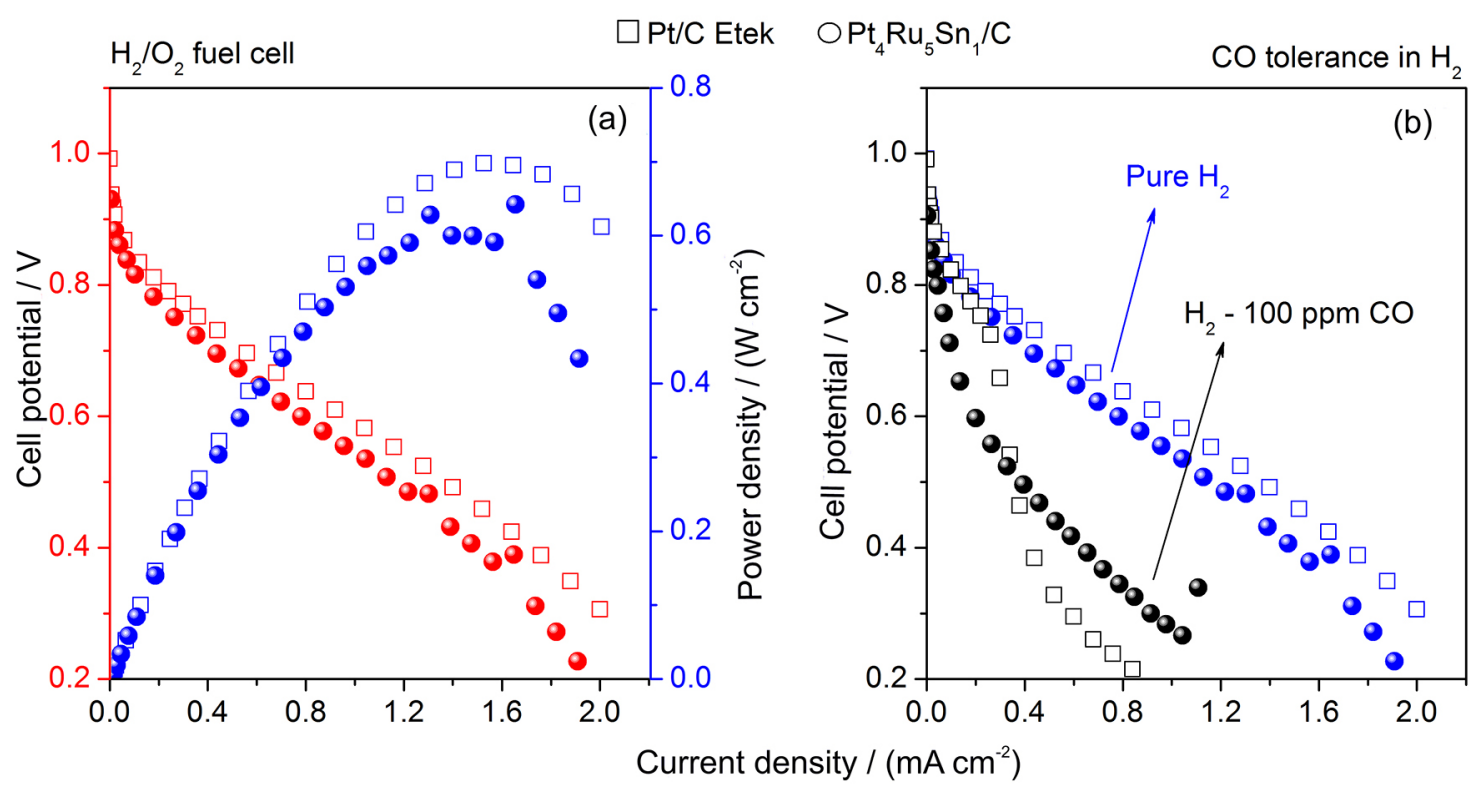

Figure 3. Cell potential and power density versus current densities for acid single cells operating at $25^{\circ} \mathrm{C}$ for Pt/C E-ETEK and $\mathrm{Pt}_{4} \mathrm{Ru}_{5} \mathrm{Sn}_{1} / \mathrm{C}$ electrodes in the absence (a) and presence (b) of CO.

terms of CbC since 1986 for Pt/C (Figure 4a) whereas the absence of $\mathrm{Ru}$ in stock exchange, ${ }^{35}$ at least under our concern, limited the oldest power density of $\mathrm{Pt}_{4} \mathrm{Ru}_{5} \mathrm{Sn}_{1} / \mathrm{C}$ to 1992 (Figure 4b).

$\mathrm{Pt}_{4} \mathrm{Ru}_{5} \mathrm{Sn}_{1} / \mathrm{C}$ generate higher power per US\$ than $\mathrm{Pt} / \mathrm{C}$ for the whole range of current densities. This color map surface allows us to investigate how the cost of power fluctuates over the years, which is important information from the technological point of view. Using $\mathrm{CbC}$, industrials can compare market viability of producing a multi-metallic nanomaterial. Although the power density $\left(\mathrm{W} \mathrm{cm}^{-2}\right)$ is slightly higher for $\mathrm{Pt} / \mathrm{C}$ than for $\mathrm{Pt}_{4} \mathrm{Ru}_{5} \mathrm{Sn}_{1} / \mathrm{C}$ (Figure 3a),

(a) $\mathrm{Pt} / \mathrm{C}$

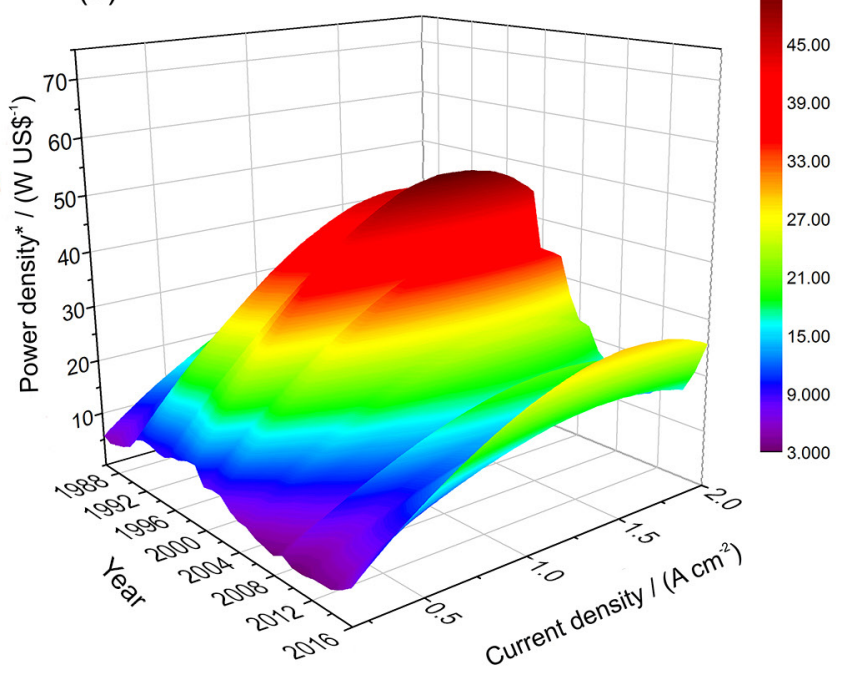

the intrinsic price of power pushes up the activity of the multi-metallic catalyst (Figure 4).

Figure 5 shows the power density in terms of $\mathrm{CbC}$ over the years at three current densities. The low price of $\mathrm{Ru}$ and the extremely low price of $\mathrm{Sn}$ make the power density of $\mathrm{Pt}_{4} \mathrm{Ru}_{5} \mathrm{Sn}_{1} / \mathrm{C}$ higher over the years. However, in some periods the high cost of metals makes the power density of Pt/C nearer to the multi-metallic NPs. The increase of the price of Pt and Ru between 2005 and 2008 makes the power densities of both catalysts closer, especially at $0.5 \mathrm{~mA} \mathrm{~cm}^{-2}$ (Figure 5a). Through the 90's, the prices of Ru and $\mathrm{Sn}$ were too low and the power density of the ternary
(b) $\mathrm{Pt}_{4} \mathrm{Ru}_{5} \mathrm{Sn}_{1} / \mathrm{C}$

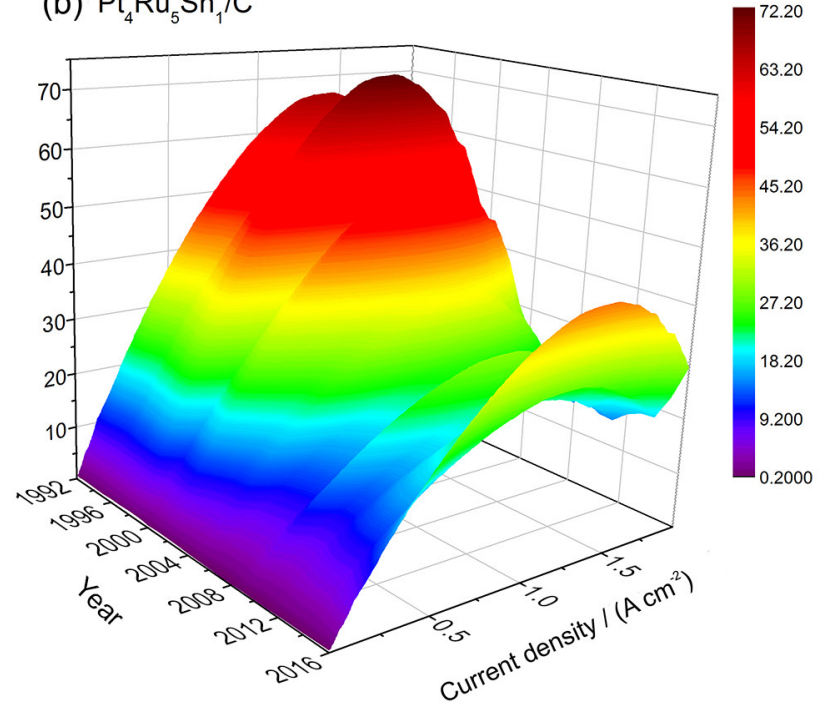

Figure 4. Fuel cell power density (W US\$ ${ }^{-1}$ ) versus current densities over the years, (a) from 1986 to 2016 for Pt/C electrode, *the catalyst-based cost of power of PEMFC over the years; (b) from 1992 to 2016 for $\mathrm{Pt}_{4} \mathrm{Ru}_{5} \mathrm{Sn}_{1} / \mathrm{C}$ electrodes. 

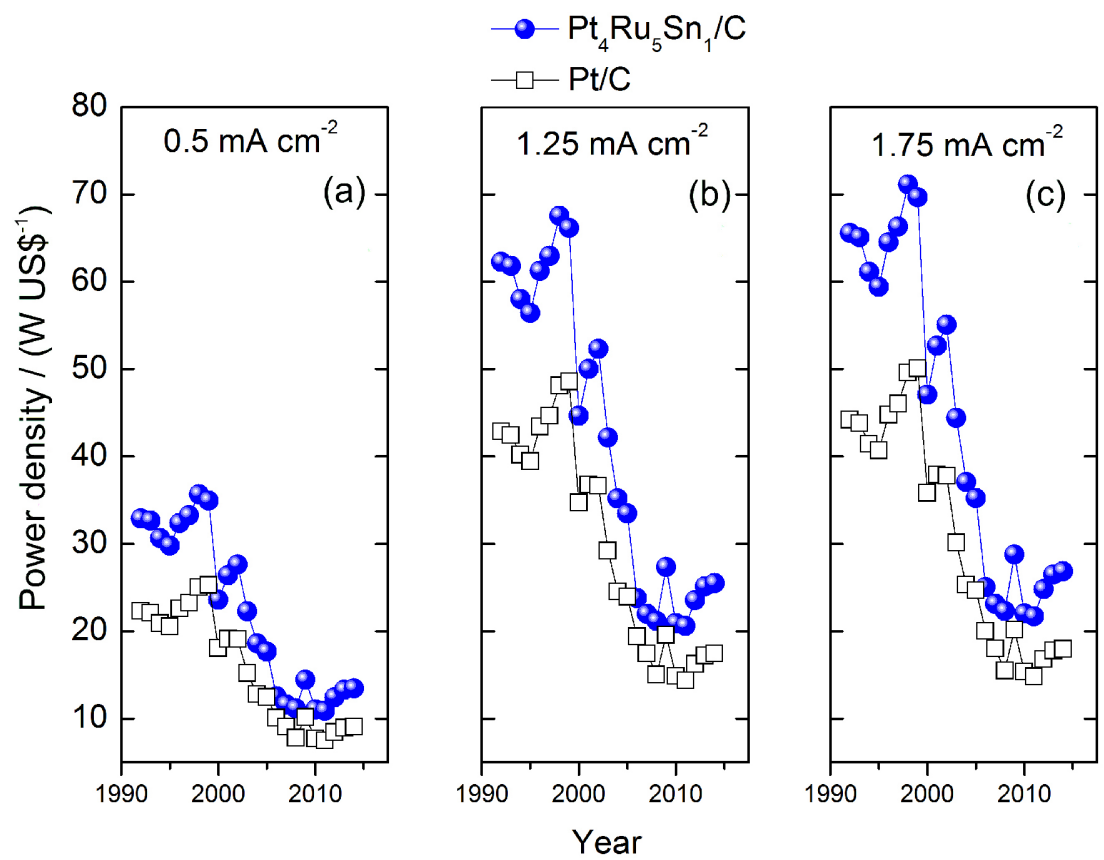

Figure 5. Fuel cell power density (W US\$-1) from 1992 to 2014 at (a) 0.5 ; (b) 1.25 ; (c) $1.75 \mathrm{~mA} \mathrm{~cm}^{-2}$.

catalyst was 1.5 times higher than Pt/C in 1997, at 1.25 and $1.75 \mathrm{~mA} \mathrm{~cm}^{-2}$ (Figures $5 \mathrm{~b}$ and $5 \mathrm{c}$ ).

This discussion shows us that the relevance of these results is relative and depends on multiple factors, most of them usually far from the fuel cells researchers' scope. In this context, it is desirable that works intending to contribute in the designing of catalysts with improved performance for fuel cell technology, present the data in a friendly manner, providing the tools to easily compare different materials performances along the years. The complexity involved in the formation of a commodity price relies on a plethora of factors that a company itself cannot directly affect, such as global supply and demand, political contingencies and so on, but the company might predict. The commodity price must not be ignored in applied science, since the literature always claims that decrease of price (for a material or process) is justification to develop a scientific project and publish those data.

One reasonable alternative to predict future prices is applying time series techniques as proposed in this paper. Here, those prices collected in stock exchanges were firstly deflated using consumer price indexes (CPI) in order to correct the inflation in the period and bring all prices to their current values. However, it is important to mention that this kind of procedure works only with past information, which means that any future abrupt movement in the industry will not be captured (but the calculation might be easily corrected whenever necessary).

Additionally to the investigation of previous years, it is possible to forecast the price of metals and consequently, predict the future price of power produced by a specific nanomaterial. To forecast the price of metals until October 2016, we used an exponential smoothing method known as Holt-Winters forecasting system, initially proposed by Charles C. Holt ${ }^{36}$ and Peter R. Winters ${ }^{37}$ on the prices of metals along the years, obtained from a stock exchange for $\mathrm{Pt},{ }^{1} \mathrm{Ru}^{35}$ and $\mathrm{Sn} .{ }^{38} \mathrm{~A}$ linear programming technique was used in order to minimize the exponential smoothing parameters ( $\alpha$-level, $\beta$-trend, $\gamma$-seasonality) and consequently the mean square error of each time series. Given the behavior of the prices in the time series, Holt-Winters multiplicative seasonal method was applied for a cycle of 12 months (period of prediction). By looking at mean square errors (Table 1), and considering numerous uncertainties that may affect the formation of a price, the model seems quite accurate, where the highest error (for $\mathrm{Ru}$ ) is ca. 9.5\%. For additional information about formulation and other exponential smoothing forecasting systems, we suggest consulting the work of Everett S. Gardner Jr. ${ }^{39}$ Curves of the real and simulated

Table 1. Holt-Winters multiplicative seasonality model applied on a time series for platinum, ruthenium and tin; parameters analysis and mean square error (SD)

\begin{tabular}{lcccc}
\hline Metal & & Platinum & Ruthenium & Tin \\
\hline Parameter & Alpha & 0.990 & 0.990 & 0.990 \\
& Beta & 0.010 & 0.494 & 0.010 \\
Gamma & 0.166 & 0.707 & 0.559 \\
Mean square error / \% & 3.413 & 9.454 & 4.092 \\
\hline
\end{tabular}


prices are superposed, which confirmed the accuracy of the method, as shows Figure S1.

The power density in terms of $\mathrm{CbC}$ shows that until the end of 2016, $\mathrm{Pt}_{4} \mathrm{Ru}_{5} \mathrm{Sn}_{1} / \mathrm{C}$ NPs will produce lower price power than $\mathrm{Pt} / \mathrm{C}$, considering a stable market, as shows the forecast activity in Figure 4 (considering the annual average prices of metals). Economists and market engineers should work together with chemists in an attempt to improve this approach to predict the activity of nanomaterials in a more distant future.

The actual methods used to normalize electrochemical currents and powers are important and should be used more carefully, highlighting the method and the reason of the choice. Our approach narrows the industrial gap, turning closer fundamental and applied science. Although, studies concerning the fluctuation of price in metal commodities stock exchange are needed, $\mathrm{CbC}$ is an additional reliable method to $(i)$ normalize electrochemical currents and to (ii) normalize powers of single fuel cells in a more applied investigation. Our approach has a clear advantage of allowing the prediction of the cost of power in terms of the global cost of all metals, which could be extended to the cost of a single fuel cell, considering that one knows how the prices of all components fluctuate, including membranes and small parts.

\section{Conclusions}

We showed that different methods of electrochemical current normalization might provide mismatched information. Using classic widespread methods, as active surface area, Pt-mass and a combination of both, we found that controversial interpretation can be made when comparing the activity of a multi-metallic catalyst with a standard one $\left(\mathrm{Pt}_{4} \mathrm{Ru}_{5} \mathrm{Sn}_{1} / \mathrm{C}\right.$ vs. homemade $\left.\mathrm{Pt} / \mathrm{C}\right)$.

Since the development of a new material to be used in energy converters aims reducing costs and maximizing the efficiency, we proposed a new method to normalize electrochemical current and power in terms of the total cost of the catalyst, named Catalyst-based Cost method ( $\mathrm{CbC}$ ). The advantage of $\mathrm{CbC}$ method is considering the price of all metals used, not only the materials with available active sites. When using the electrochemically active surface area, those metals not available for reaction are not taken into account, although they contribute to the global cost of the catalyst.

The $\mathrm{CbC}$ method was used to estimate the activity of $\mathrm{Pt}_{4} \mathrm{Ru}_{5} \mathrm{Sn}_{1} / \mathrm{C}$ and homemade $\mathrm{Pt} / \mathrm{C}$ along the years by using the price of the nanocatalysts calculated from the price per gram of each metal obtained from a stock exchange. An analysis of the power density in terms of
Watt per US\$ of $\mathrm{H}_{2} / \mathrm{O}_{2}$ single cells showed that an anode made of $\mathrm{Pt}_{4} \mathrm{Ru}_{5} \mathrm{Sn}_{1} / \mathrm{C}$ is more advantageous than $\mathrm{Pt} / \mathrm{C}$ since 1992 until nowadays. Moreover, some fluctuations of price allowed the power density of the fuel cell built with $\mathrm{Pt} / \mathrm{C}$ to be closer to that using $\mathrm{Pt}_{4} \mathrm{Ru}_{5} \mathrm{Sn}_{1} / \mathrm{C}$ in particular periods.

By applying a simple smoothing method on the prices along the years we were able to forecast the price of the metals one year in the future. Consequently, our method provides the possibility of forecasting the price of power in terms of catalyst cost, which is important from the technological point of view. Industrials can decide from which material the anode of a fuel cell should be made for the next year. Our results showed that the multi-metallic catalyst is still a good choice for the next twelve months. Furthermore, $\mathrm{CbC}$ method could be used for any interfacial process involving metallic nanoparticles to forecast the efficiency of the process in terms of price.

\section{Supplementary Information}

Supplementary information is available free of charge at http://jbcs.sbq.org.br as a PDF file.

\section{Acknowledgments}

The authors acknowledge financial assistance from CNPq (grant No. 454516/2014-2), FUNDECT (grant No. 026/2015), CAPES and FINEP.

\section{References}

1. Quotes of Platinum, available at http://www.kitco.com, accessed in March 2016.

2. Lin, C.-L.; Wang, C.-C.; Appl. Energy 2016, 164, 1043.

3. Lin, R.; Cao, C.; Zhang, H.; Huang, H.; Ma, J.; Int. J. Hydrogen Energy 2012, 17, 4648.

4. Liang, Q.; Zhang, L.; Cai, M.; Li, Y.; Jiang, K.; Zhang, X.; Shen, P. K.; Electrochim. Acta 2013, 111, 275.

5. Zhang, Y.; Ma, C.; Zhu, Y.; Si, R.; Cai, Y.; Wang, J. X.; Adzic, R. R.; Catal. Today 2013, 202, 50.

6. Hsu, C.; Huang, C.; Hao, Y.; Liu, F.; Electrochem. Commun. 2012, 23, 133.

7. Yang, Y.; Wang, W.; Liu, Y.; Wang, F.; Chai, D.; Lei, Z.; Electrochim. Acta 2015, 154, 1.

8. Singh, R. N.; Awasthi, R.; Catal. Sci. Technol. 2011, 1, 778.

9. Antolini, E.; J. Power Sources 2007, 170, 1.

10. Geng, D.; Lu, G.; J. Phys. Chem. C 2007, 111, 11897.

11. Wei, Y. C.; Liu, C. W.; Kang, W. D.; Lai, C. M.; Tsai, L. D.; Wang, K. W.; J. Electroanal. Chem. 2011, 660, 64.

12. Lima, F. H. B.; Profeti, D.; Chatenet, M.; Riello, D.; Ticianelli, E. A.; Gonzalez, E. R.; Electrocatalysis 2010, 1, 72. 
13. Chen, H.; Huang, Y.; Tang, D.; Zhang, T.; Wang, Y.; Electrochim. Acta 2015, 158, 18 .

14. Permyakova, A. A.; Han, B.; Jensen, J. O.; Bjerrum, N. J.; Shao-Horn, Y.; J. Phys. Chem. C 2015, 119, 8023.

15. Rodriguez, P.; Garcia-Araeza, N.; Koper, M. T. M.; Phys. Chem. Chem. Phys. 2010, 12, 9373.

16. Cui, Z.; Kulesza, P. J.; Li, C. M.; Xing, W.; Jiang, S. P.; Int. J. Hydrogen Energy 2011, 36, 8508.

17. Thepkaew, J.; Therdthianwong, S.; Therdthianwong, A.; Kucernak, A.; Wongyao, N.; Int. J. Hydrogen Energy 2013, 38, 9454.

18. Wu, G.; Swaidan, R.; Cui, G.; J. Power Sources 2007, 172, 180.

19. Trongchuankij, W.; Pruksathorn, K.; Hunsom, M.; Appl. Energy 2011, 88, 974.

20. Shen, S.; Zhao, T.; J. Mater. Chem. A 2013, 1, 906.

21. He, F.; Yang, J.; Li, R.; Liu, B. H.; Li, Z. P.; J. Power Sources 2015, 274, 48.

22. Pinto, L. M. C.; Juárez, M. F.; Ângelo, A. C. D.; Schmickler, W.; Electrochim. Acta 2014, 116, 39.

23. Ahmed, M. S.; Jeon, S.; ACS Catal. 2014, 4, 1830.

24. Purgato, F. L. S.; Olivi, P.; Léger, J. M.; de Andrade, A. R.; Tremiliosi-Filho, G.; Gonzalez, E. R.; Lamy, C.; Kokoh, K. B.; J. Electroanal. Chem. 2009, 628, 81.

25. Lomocso, T. L.; Baranova, E. A.; Electrochim. Acta 2011, 56, 8551.

26. Li, M.; Cullen, D. A.; Sasaki, K.; Marinkovic, N. S.; More, K.; Adzic, R. R.; J. Am. Chem. Soc. 2013, 135, 132.

27. Purgato, F. L. S.; Pronier, S.; Olivi, P.; de Andrade, A. R.; Léger, J. M.; Tremiliosi-Filho, G.; Kokoh, K. B.; J. Power Sources 2012, 198, 95.
28. Ribeiro, J.; dos Anjos, D. M.; Kokoh, K. B.; Coutanceau, C.; Léger, J.-M.; Olivi, P.; de Andrade, A. R.; Tremiliosi-Filho, G.; Electrochim. Acta 2007, 52, 6997.

29. Loukrakpam, R.; Yuan, Q.; Petkov, V.; Gan, L.; Rudi, S.; Yang, R.; Huang, Y.; Brankovic, S. R.; Strasser, P.; Phys. Chem. Chem. Phys. 2014, 16, 18866.

30. Kozlowska, H. A.; Comprehensive Treatise of Electrochemistry, Vol. 9; Yeager, E. B.; Bockris, J. O.'M.; Conway, B. E.; Sarangapani, S., eds.; Plenum Press: New York, 1981, pp. 2.

31. Bligaard, T.; Nørskov, J. K.; Electrochim. Acta 2007, 52, 5512.

32. Barbosa, A. F. B.; Oliveira, V. L.; van Drunen, J.; TremiliosiFilho, G.; J. Electroanal. Chem. 2015, 746, 31.

33. Kim, H. J.; Choi, S. M.; Green, S.; Tompsett, G. A.; Lee, S. H.; Huber, G. W.; Kim, W. B.; Appl. Catal., B 2011, 101, 366.

34. Ehteshami, S. M. M.; Chan, S. H.; Electrochim. Acta 2013, 93, 334.

35. http://www.platinum.matthey.com, accessed in March 2016.

36. Holt, C. C. In Forecasting Seasonals and Trends by Exponentially Weighted Moving Averages; ONR Memorandum, Carnegie Institute of Technology: Pittsburgh, PA, 1957.

37. Winters, P. R.; Manage. Sci. 1960, 6, 324.

38. http://www.worldbank.org/prospects, accessed in March 2016.

39. Gardner Jr., E. S.; Int. J. Forecast. 2006, 22, 637.

Submitted: January 19, 2016

Published online: March 22, 2016

FAPESP has sponsored the publication of this article. 